\title{
Graphene-Chitosan Hybrid Dental Implants with Enhanced Antibacterial and Cell-Proliferation Properties
}

\author{
Sunho Park ${ }^{1,+}{ }^{+}$Hyeran Kim ${ }^{2,+}$, Kyoung Soon Choi ${ }^{3}{ }^{\circledR}$, Min-Kyung Ji ${ }^{4}$, Sujin Kim ${ }^{1}$, \\ Yonghyun Gwon ${ }^{1}$, Chan Park ${ }^{2}{ }^{\oplus}$, Jangho Kim ${ }^{1, *}$ and Hyun-Pil Lim ${ }^{2, *}$ \\ 1 Department of Rural and Biosystems Engineering, Chonnam National University, Gwangju 61186, Korea; \\ preference9330@gmail.com (S.P.); kimsujin4172@gmail.com (S.K.); gyhjhj0716@gmail.com (Y.G.) \\ 2 Department of Prosthodontics, School of Dentistry, Chonnam National University, 77, Yongbong-ro, Buk-gu, \\ Gwangju 61186, Korea; ddsrankim@gmail.com (H.K.); upgradepc@hanmail.net (C.P.) \\ 3 National Research Facilities \& Equipment Center (NFEC), Korea Basic Science Institute (KBSI), \\ 169-148 Gwahak-ro, Yuseong-gu, Daejeon 34133, Korea; kschoi@kbsi.re.kr \\ 4 Optoelectronics Convergence Research Center, Chonnam National University, Gwangju 61186, Korea; \\ perizimin@gmail.com \\ * Correspondence: rain2000@jnu.ac.kr (J.K.); mcnihil@jnu.ac.kr (H.-P.L.) \\ $+\quad$ S.P. and H.K. contributed equally to this work.
}

Received: 12 June 2020; Accepted: 13 July 2020; Published: 16 July 2020

\begin{abstract}
Dental implants are widely used tooth replacement tools owing to their good oral rehabilitation and reconstruction capacities. Since dental implants are designed as a replacement for natural teeth, multi-functional abilities are desired to achieve successful implant treatment with improved osseointegration through promotion of mammalian cell activity and prevention of bacterial cell activity. In this study, we developed a graphene-chitosan hybrid dental implant (GC hybrid implant) using various concentrations of graphene, which demonstrated the different surface properties including increased wettability and roughness. Importantly, the GC hybrid implant under the optimal condition (i.e., 1\% GC hybrid implant) could significantly promote osteoblast proliferation while reducing biofilm formation and bacterial activity. Our study demonstrates the potential of using this GC hybrid implant as a new type of dental implant, which can offer an effective design for the fabrication of advanced dental implants.
\end{abstract}

Keywords: dental implant; graphene oxide; chitosan; titanium

\section{Introduction}

Dental implants are used as a permanent substitution for natural teeth for oral rehabilitation when edentulous patients have no other alternative to replace the tooth at the edentulate site. With advances in modern dental implantology, dental implants are fabricated using various materials, and new surgical techniques have been proposed to increase the success rate of dental implant treatment [1-3]. Metallic materials have gradually become the most widely used materials for dental implants owing to their stable mechanical property, high corrosion resistance, and suitable biocompatibility $[4,5]$. Despite these advantages of metallic materials, the incomplete osseointegration between the implant surface and transplanted site remains a critical problem after dental implant treatment [2,6]. Davies [7] proposed an ideal osseointegration period of 3-6 months after a successful implant operation; however, patients have to endure masticatory difficulty during the osseointegration period. Moreover, the soft tissue and bone are more susceptible to periodontitis during this time, which stimulates inflammation and bone loss, requiring antibiotic treatment and may ultimately result in implant failure [8]. Lindhe 
and Meyle [9] revealed that the risks of peri-implant mucositis are about $80 \%$ in patients and the risks of peri-implantitis are about $28 \sim 56 \%$ in patients, following dental implant surgery.

Therefore, it is a challenge to develop an ideal dental implant that can effectively promote osseointegration while suppressing bacterial biofilm formation and activity. Surface treatment of a dental implant is regarded as an essential process to control the structural property, and several commercial dental implants have been developed with various surface modifications, including plasma spraying, resorbable blasted media, acid etching, and oxidation $[2,10,11]$. The advantages of surface treatment include: (i) improvement of the mechanical fixation of the implant during placement, (ii) proper structure formation for blood clot maintenance, and (iii) promotion of bone healing [12]. These surface modifications can accelerate osseointegration along with preventing biofilm formation $[13,14]$. In addition, different biochemical materials, including proteins, drugs, and biomolecules, have gradually been used to improve local delivery on the surface of a metallic implant [15-17]. Kim et al. [18] investigated the effects of a growth factor-loaded titanium implant on osseointegration. Bone morphogenetic protein (BMP) is the key factor for inducing differentiation into osteoblasts to promote bone regeneration. Using an immersion technique, BMPs at various concentrations were successfully loaded onto the surfaces of a titanium implant that was sand-blasted with large grit and acid-etched, and the optimal concentrations of BMPs $(0.5$ and $1.0 \mathrm{mg} / \mathrm{mL})$ were found to be effective for inducing bone regeneration and osseointegration in a beagle dog model. In addition to this study, various other traditional approaches (i.e., structural and biochemical treatments) have been proposed to improve the functions of a dental titanium implant.

Graphene is regarded as a new carbon-based nanomaterial on the threshold of the silicon age, and its potential for various fields has been widely acknowledged, including chemical, biomedical, environmental, and electrical fields $[19,20]$. In our previous research, we used graphene as a stem cell culture substrate [21,22]. Human adipose-derived stem cells (hASCs) were cultured on a graphene film, and the affinity of hASCs on the graphene film was induced under the fluid shear stress of a rocking culture system. The differentiation of hASCs into specific lineages, including osteogenic, adipogenic, and epithelial lineages, was strongly promoted in the presence of graphene. In addition, human mesenchymal stem cells (hMSCs) were cultured on graphene-incorporated chitosan substrates with various concentrations of graphene [22]. The surface coverage and roughness were increased with an increasing concentration of graphene, and the cell attachment of hMSCs on graphene-chitosan (GC) substrates was promoted. Although the proliferation of hMSCs on a $0.05 \%$ GC substrate was better than that on substrates with a higher concentration, the osteogenic differentiation of hMSCs was slightly accelerated on substrates with higher graphene concentrations (i.e., $0.5 \%$ or $5 \%$ ). To further confirm the effects of graphene on the initial cell behavior, the expression of integrin beta- 1 and $C \times 43$ was investigated. Interestingly, the expression levels were greatly increased in the presence of graphene, indicating that the initial cell-substrate interaction and cell-cell communication were enhanced by graphene, which might lead to the promotion of osteogenic differentiation.

These findings demonstrate the advantages of graphene for achieving good biocompatibility and bioactivity, which can further promote cell functions and behaviors at the optimal concentration. Therefore, graphene has been gradually incorporated into the design of bone-related implants. Li et al. [23] investigated the osseointegration of a chemical vapor deposition (CVD) graphene-coated titanium alloy using rabbit models. The animals that received the CVD graphene-coated titanium alloy showed an improved bone volume, mineral apposition rate, and new bone formation rate due to enhanced surface biological activity. Qiu et al. [24] demonstrated that the coating of graphene on titanium might suppress bacterial activity, and the surfaces that were completely covered with graphene could prevent not only the adherence of bacteria but also biofilm formation.

In this study, we propose a rational design for the fabrication of graphene-based hybrid dental implants using a facile spin-coating technique. To this end, the fabricated hybrid dental implant was formed into graphene-incorporated structures, which provided suitable surface properties for promoting osseointegration, such as increased wettability and roughness. We further demonstrate that 
the changed surface properties of the hybrid implant can control the functions of both mammalian and bacterial cells, offering a new design for a dental implant.

\section{Materials and Methods}

\subsection{Materials}

Highly pure graphite was purchased from Alfa Aesar (Massachusetts, MA, USA). Chitosan with a low molecular weight was purchased from YB Bio Co. Ltd. (Seoul, Korea). All other reagents were purchased from Sigma-Aldrich (St. Louis, MO, USA).

\subsection{Fabrication of the Graphene-Chitosan (GC) Hybrid Implant}

Pure titanium disks (ASTM Grade IV, $3 \mathrm{~mm}$ thickness and $15 \mathrm{~mm}$ diameter; Kobe Steel, Kobe, Japan) were polished by grinding and using polishing equipment (Labopol-5, Struers, Ballerup, Denmark); \#600 and \#1500 SiC polishing papers were used for titanium surface treatment. The polished titanium disks were then washed with acetone, $75 \%$ ethanol, and deionized water (DI water) using an ultrasonic cleaner (WUC- D03H, DAIHAN-brand, Wonju, Korea). Graphene oxide (GO) was fabricated according to the modified Hummer method [25], and the fabricated GO powder was sonicated in DI water for $3 \mathrm{~h}$. Subsequently, chitosan powder (3\%) was dissolved in $1 \%$ acetic acid solution for $6 \mathrm{~h}$, and GO solutions (1\%, 3\%, and 5\%) were homogeneously blended with the chitosan solution. The prepared GC solutions were then spin-coated onto the surface of the prepared titanium disks (Spin coater, ACE-200, DONG AH, Seoul, Korea) under the following conditions: (i) the titanium disk was rotated at $500 \mathrm{rpm}$ for $15 \mathrm{~s}$ after acceleration for $2.5 \mathrm{~s}$; (ii) rotation was continued at $1000 \mathrm{rpm}$ for $15 \mathrm{~s}$ after acceleration for $2.5 \mathrm{~s}$; and (iii) rotation was performed at $4000 \mathrm{rpm}$ for $10 \mathrm{~s}$ after acceleration for $2.5 \mathrm{~s}$.

\subsection{Characterization of the GC Hybrid Implant}

Laser Raman spectrophotometric measurements were obtained with an NRS-5100 instrument (JASCO, Tokyo, Japan) at $532.13 \mathrm{~nm}$. The water contact angles were analyzed with a video contact angle measuring device (Phoenix 300, SEO, Selangor D.E., Malaysia). Scanning electron microscopy (SEM) imaging was performed using a JSM-7500F field-emission scanning electron microscope (FE-SEM S-4700, Hitachi horiba, Kyoto, Japan). The roughness measurements were obtained with a nanosurface 3D optical profiler (NV-E1000, Nano System, Daejeon, Korea). The fluorescent images were acquired with a laser confocal-scanning microscope (Leica TCS SP5 AOBS/tandem, Leica, Wetzlar, Germany).

\subsection{Osteoblast Proliferation Tests}

The prepared hybrid implant was washed three times using ethanol $(70 \%)$ and once using $1 \times$ phosphate-buffered saline (PBS). The washed sample was then treated with alpha-minimum essential medium (Gibco-BRL, Grand Island, NY, USA) containing 10\% fetal bovine serum and $100 \mu \mathrm{g} / \mathrm{mL}$ penicillin for $3 \mathrm{~h}$ before use. MC3T3-E1 cells were then seeded onto the scaffolds $\left(4 \times 10^{4}\right.$ cells/sample) at $37{ }^{\circ} \mathrm{C}$ under a humidified atmosphere with $5 \% \mathrm{CO}_{2}$ (Forma Series II 3111 Water Jacketed $\mathrm{CO}_{2}$ Incubator, Thermo Scientific, Illinois, USA). After culturing for $6 \mathrm{~h}$ (cell attachment) and 5 days (cell proliferation), the samples were treated with 1\% WST assay solution (4-[3-(4-Iodophenyl)-2-(4-nitrophenyl)-2H-5-tetrazolio]-1,3-benzene Disulfonate, EZ-Cytox, Itsbio, Inc., Seoul, Korea). After $3 \mathrm{~h}$, the optical density of $100 \mu \mathrm{L}$ media was confirmed by enzyme-linked immunosorbent assay (ELISA; VersaMax ELISA Microplate Reader, Molecular Device, Sunnyvale, CA, USA) at $450 \mathrm{~nm}$. For SEM imaging of the osteoblasts, the MC3T3-E1 cells $\left(4 \times 10^{4}\right.$ cells/sample) were seeded on the scaffolds and cultured. After culturing for $6 \mathrm{~h}$ and 5 days, the cells were fixed with $2.5 \%$ glutaraldehyde for $2 \mathrm{~h}$ and then washed using PBS twice. The fixed samples were dehydrated in a series of ethanol concentrations $(40 \%, 50 \%, 60 \%, 70 \%, 80 \%, 90 \%$, and $100 \% v / v)$ for $5 \mathrm{~min}$. The samples were dried for platinum coating and SEM observations. 


\subsection{Anti-Biofilm Formation Tests}

To confirm the anti-biofilm formation effect, the prepared hybrid implant was treated with artificial saliva, containing 1\% mucin from the porcine stomach (M1778; Sigma-Aldrich, St Louis, MO, USA) and adherence buffer (Table S1), for $2 \mathrm{~h}$. Streptococcus mutans KCOM 1504 (Korean Collection for Oral Microbiology $[\mathrm{KCOM}]$, Gwangju, Korea), which is a representative Gram-positive bacterium, was used for the anti-biofilm formation test, which was cultured in brain heart infusion medium (Becton, Dickinson and Company, Sparks, MD, USA) at $37^{\circ} \mathrm{C}$ in an incubator (LIB-150M, DAIHAN Labtech Co., Wonju, Korea). The bacteria were stained using green fluorescent nucleic acid stain (SYTO 9, Molecular Probes Europe BV, Leiden, The Netherlands) and red fluorescent nucleic acid stain (propidium iodide, Molecular Probes Europe BV, Leiden, The Netherlands) for $24 \mathrm{~h}$. The unattached bacteria were removed by washing with PBS, followed by treatment with $200 \mu \mathrm{L} / \mathrm{mL}$ SYTO 9 solution $\left(\mathrm{dH}_{2} \mathrm{O}=3 \mu \mathrm{L}: 2 \mathrm{~mL}\right)$ for $15 \mathrm{~min}$. The stained bacteria were washed with PBS and the samples were dried at room temperature. To quantify the bacteria, $0.3 \%$ crystal violet solution was reacted with the samples for $10 \mathrm{~min}$. After PBS washing, the samples were dried for $15 \mathrm{~min}$ and then treated with $500 \mu \mathrm{L} / \mathrm{mL}$ ethyl alcohol/acetone (8:2 solution) for $1 \mathrm{~h}$. The optical density of $200-\mu \mathrm{L}$ samples of the reacted media was measured by ELISA (VersaMax ELISA Microplate Reader, Molecular Device, Winooski, USA) at $595 \mathrm{~nm}$.

\subsection{Statistical Analysis}

Statistical analysis was conducted with SPSS 21.0 software (SPSS Inc., Chicago, IL, USA), and one-way analysis of variance (ANOVA), Shapiro-Wilk, and Turkey test. In all cases, $p$ values of $<0.05$ were considered statistically significant. All quantitative results are presented as the mean \pm standard deviation.

\section{Results}

\subsection{Fabrication and Characterization of the GC Hybrid Implant}

To confirm the effects of GC coating on the titanium, we used pure titanium discs as a model implant. The GC solution was applied onto the surface of titanium discs through a spin-coating technique to improve the functionality of pure titanium as a dental implant (e.g., improved cell attachment and anti-biofilm formation). The hybrid implants were fabricated with three different concentrations of GC solution (1\%, 3\%, and 5\%) and one chitosan solution-treated surface was also prepared as a control. To confirm the presence of GO on the surfaces of the hybrid implants, Raman spectroscopy analysis was conducted. Figure 1a shows the Raman spectra of the 1\%, 3\%, and 5\% GC hybrid implants, demonstrating representative peaks of GO at the G and D peaks (near 1350 and $1590 \mathrm{~cm}^{-1}$ ). The $\mathrm{G}$ peak indicates an in-plane vibration from the $\mathrm{sp}^{2}$ hybridization of well-ordered materials, and the $\mathrm{D}$ peak represents the out-of-plane vibration from the $\mathrm{sp}^{3}$ bonding and structural defects [26]. This result demonstrated that the surfaces of the hybrid implant were successfully integrated with GO. Next, we investigated the water contact angle and the roughness. The surface properties, including suitable wettability and roughness, are essential to improve cell attachment and to suppress bacteria attachment [27-29]. As shown in Figure 1b,c, the contact angle of the chitosan solution-coated titanium was $61.5^{\circ}$, and the contact angles of the GC hybrid implants were $56.2^{\circ}$ ( $1 \%$ GC), $54.6^{\circ}(3 \% \mathrm{GC})$, and $54.5^{\circ}$ (5\% GC). The average roughness was $114.6 \pm 7.9 \mathrm{~nm}$ for the chitosan-coated surface, $124.6 \pm 4.7 \mathrm{~nm}$ (1\% GC), $140.7 \pm 8.8 \mathrm{~nm}(3 \%$ GC), and $149.0 \pm 7.2 \mathrm{~nm}(5 \% \mathrm{GC})$. Interestingly, the wettability and roughness were directly changed by the concentration of graphene, with a gradual increase as the concentration of graphene increased. Therefore, by combining the graphene and chitosan solutions, the surface properties, including wettability and roughness, were successfully controlled. 
a

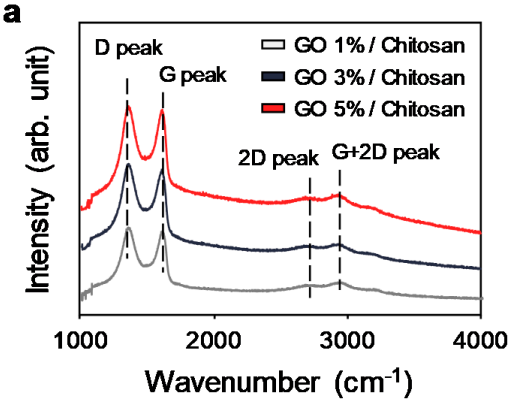

b

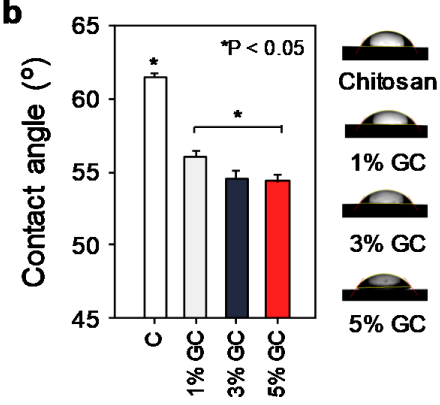

c

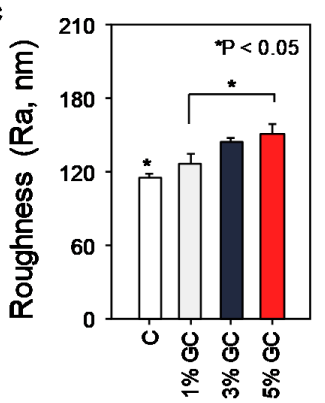

Figure 1. Characterization of the graphene-chitosan (GC) hybrid implants (1\%, 3\%, 5\% GC) and chitosan (C) hybrid implant. (a) Raman spectra, (b) water contact angle, and (c) roughness measurement. The data were analyzed using one-way analysis of variance (ANOVA) $\left({ }^{*} p<0.05\right)$.

\subsection{Effects of the GC Hybrid Implant on Biofilm Formation}

The activation of bacteria is detrimental to implant placement, and the suppression of biofilm formation is crucial for the stable establishment of a titanium implant. Various bacteria are present in the mouth, which rapidly form a biofilm. S. mutans is a representative gram-positive bacterium, and it can stimulate early biofilm formation. To confirm the anti-biofilm formation property of the GC hybrid implant visually, fluorescent nucleic acid staining was used. The live bacteria cells were stained with green fluorescent nucleic acid stain and the dead bacteria cells were stained with red fluorescent nucleic acid stain. As shown in Figure 2a, the substrates of the 1\% GC hybrid implant were entirely stained by red fluorescence, whereas the substrates of the chitosan-coated implant were mainly stained by green fluorescence. The results of the biofilm thickness formation assay indicated that biofilm formation was inhibited by graphene with a smaller concentration, and it was reduced by about half that observed on the chitosan-coated implant. In addition, the crystal violet assay demonstrated that the bacteria viability was highly regulated by the concentration of graphene, which increased as the graphene concentration increased (e.g., antibacterial effect: $1 \%$ GC $>3 \%$ GC $>5 \%$ GC $>$ chitosan). To compare the bacteria viability according to the type of substrate and bacteria, the live and dead assay was performed with both Staphylococcus aureus and S. mutans on pure glass and on the titanium substrate (Figure S1). The confocal images showed that the GC-coated substrate could moderately modulate the adherence of bacteria, and the antibacterial properties increased greatly regardless of the type of bacteria and substrates. Interestingly, the GC hybrid glass and titanium implant showed high antibacterial and anti-biofilm formation effects in contrast to pure glass and titanium.

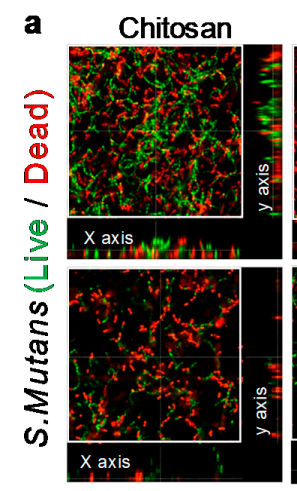

$3 \%$ GC
$1 \% \mathrm{GC}$

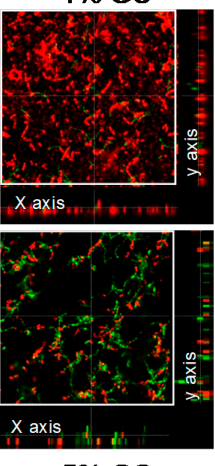

b

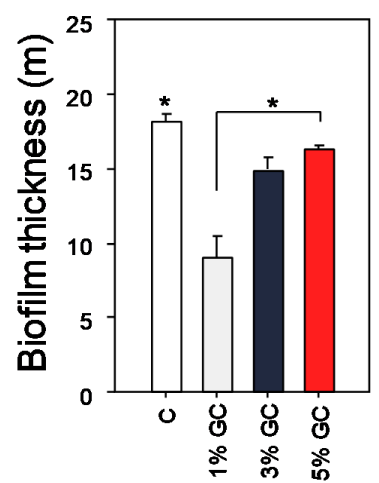

c

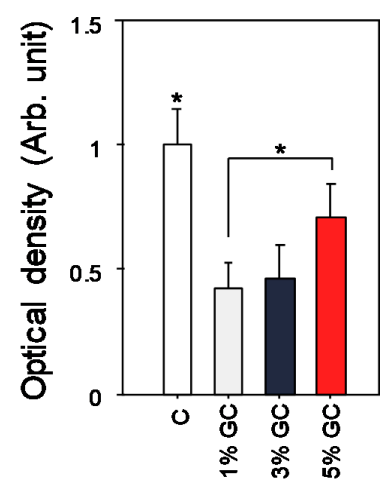

Figure 2. Effects of graphene-chitosan hybrid implants on bacteria activity. (a) Confocal microscopy images of $S$. mutans on graphene-chitosan hybrid implants (1\%, 3\%, and 5\% GC) and the chitosan implant (C). Green fluorescence indicates viable cells and red fluorescence indicates dead cells ( $n=10$ per group). $(\mathbf{b}, \mathbf{c})$ Quantification of biofilm thickness and optical density. The data were analyzed using one-way ANOVA $\left({ }^{*} p<0.05\right)$. 


\subsection{Effects of the GC Hybrid Implant on Cell Viability}

Cell attachment and proliferation on the surface of a dental implant are critical events after the replacement of natural teeth with a dental implant. To confirm the morphology of osteoblasts after cell attachment and proliferation on the surface of the prepared hybrid implant, SEM images of MC3T3-E1 cells were analyzed (Figure 3). After $6 \mathrm{~h}$, MC3T3-E1 cells were mostly attached onto the surfaces of the hybrid implant and were entangled with the GC composites. The cell viability assay showed no differences in the extent of attachment on the implant surfaces with chitosan alone and with the GC hybrid (Figure S2). After 5 days, MC3T3-E1 cells completely covered the hybrid implant surfaces, and there was a wide range of the attached cells in the presence of graphene. The cell viability assay showed the same trend, and the cell number on the GC hybrid implant was nearly 1.6 times higher than that on the chitosan titanium surface. These findings demonstrated that the treatment of chitosan or GC does not significantly affect cell attachment, but the proliferation of osteoblasts was greatly influenced by the presence of graphene.
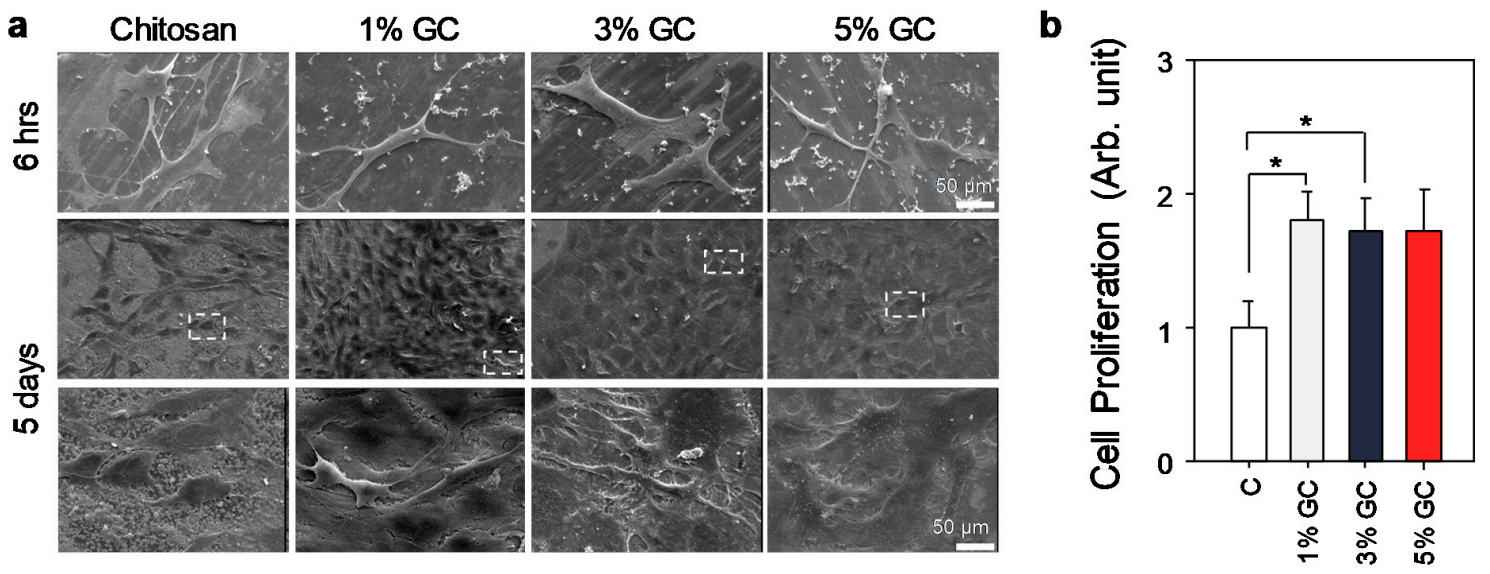

Figure 3. Effects of graphene-chitosan hybrid implants on the activity of mammalian cells. (a) Representative scanning electron microscope (SEM) images of MC3T3-E1 cells on graphene-chitosan hybrid implants (1\%,3\%, and 5\% GC) and the chitosan (C) implant. (b) Quantification of the cell proliferation of MC3T3-E1 cells ( $n=4$ per group). The data were analyzed using one-way ANOVA and Tukey's test $(* p<0.05)$.

\section{Discussion}

To develop an advanced dental implant, surface treatments are widely used, including physical and chemical methods, to provide a suitable environment for improving the quantity and quality of osseointegration. The physical method-based surface treatment can increase the surface area by increasing roughness, and chemical method-based surface treatment with biochemical materials can confer proper bioactivity to cells [30-32]. In this study, we used a material-based surface treatment, with the advantages of incorporating the two types of surface treatments (i.e., physical and chemical method-based surface treatments). Graphene has a unique physicochemical property with unparalleled nanotopographic features, and its good biocompatibility has led to its recognition as an efficient tool for improving the functions of biomaterials $[33,34]$. The various works demonstrated that the incorporation of graphene can improve the mechanical strength owing to the high surface area and unique chemical properties of graphene [33]. Zhang et al. developed the electrodeposited GO-titanium substrates, showing the enhanced mechanical properties of the fabricated GO-titanium substrates than those on the pure titanium substrates [34]. The modulus of fabricated GO-titanium substrate was increased compared to that of the hydroxyapatite-coated titanium substrate (e.g., $1.7 \mathrm{GPa}$ ), and the hardness was increased (e.g., $18 \mathrm{MPa}$ ). Park et al. [35,36] revealed that a graphene-layered eggshell membrane substrate can acquire a micro- and nanoscale hierarchical wrinkled morphology without inducing damage to the protein-based eggshell membrane, and the limitations of raw materials such as the 
structural property, chemical property, and wettability were overcome through the combination of the advantages of the two materials. Furthermore, the authors confirmed the ability of the fabricated substrates as an artificial extracellular matrix using stem cells. Interestingly, the stem cell morphologies were controlled according to varying the concentration of graphene, resulting in enhanced cytoskeleton development. In addition, the different degree of attachment of stem cells with various graphene concentrations subsequently affected the stem cell functions, including proliferation, differentiation, and the production of growth factor through cell-substrate interactions.

To suppress bacteria activity and biofilm formation, methods for controlling the wettability of a surface, such as hydrophilic and hydrophobic properties, are typically employed. In particular, a superhydrophilic and superhydrophobic surface can prevent the attachment of bacteria, which has been applied into secondary application fields, including food packaging and storage [37,38]. The proposed GC hybrid implant showed only a slightly hydrophilic surface, but biofilm formation was nonetheless inhibited. These findings showed that the structural and chemical properties of graphene can influence bacterial activity. $\mathrm{Li}$ et al. [39] investigated the antibacterial effects of a graphene-based nanocomposite, which was fabricated using simple electrostatic binding. The graphene-based nanocomposites resulted in a small inhibition zone, whereas the silver-decorated graphene nanocomposite had a greater inhibitory effect. The authors proposed that the nanoplane structure of graphene may directly penetrate the bacteria membrane as the possible inactivation mechanism. Although the mechanism underlying the indirect antibacterial effects is unclear, it was attributed to the synergistic effect of graphene with microbial-produced substances. Chitosan is a representative microbial material, and various hypotheses have been suggested for these interactions [40-43]. The first hypothesis was that chitosan has positively charged amine groups, which could directly react with the negatively charged bacterial membrane [43]. The second hypothesis is that the incorporation of chitosan with metal and nanomaterials can produce toxins that inhibit bacterial growth [42]. The third hypothesis is that chitosan on the surface of bacteria can disrupt the nutrients and oxygen available in the environment [44]. The fourth hypothesis is that the contact of chitosan with bacterial DNA allows for chitosan to penetrate the nuclei, leading to bacterial death [41].

Interestingly, the antibacterial properties and anti-biofilm formation effects were increased on the $1 \%$ GC hybrid implants (e.g., graphene concentration $=0.3 \mathrm{mg} / \mathrm{mL}$ ) compared to the $3 \%$ and $5 \%$ GC hybrid implants. Liu et al., demonstrated that the anti-bacteria effects of graphene, and they show the time-dependent (i.e., anti-bacteria effects: $4 \mathrm{~h}>2 \mathrm{~h}>1 \mathrm{~h}$ ) and concentration dependent (i.e., anti-bacteria effects: $80>40>20>10>5 \mu \mathrm{g} / \mathrm{mL}$ ) behaviors of bacteria [45]. Recently, Alayande et al. revealed the importance of GO loading concentration per area [46]. They used GO with various concentration (e.g., $0.0078 \mathrm{mg} / \mathrm{mL}, 0.0156 \mathrm{mg} / \mathrm{mL}, 0.0313 \mathrm{mg} / \mathrm{mL}, 0.0625 \mathrm{mg} / \mathrm{mL}, 0.125 \mathrm{mg} / \mathrm{mL}, 0.25 \mathrm{mg} / \mathrm{mL}$, and $0.5 \mathrm{mg} / \mathrm{mL}$ ), and high concentration of GO with the increased roughness could be generated the deep valley structure, which might cause the increased performance of bacteria attachment. In addition, they reported that the increased hydrophobic force and $\pi-\pi$ interactions between the high concentration of graphene and bacterial cell membranes may overcome the electrostatic repulsion, and the bacteria attachment was maintained on the surfaces. Taken together, these reports with our current results suggest that the GO with highly increased concentrations might trigger the attachment of bacteria, inducing the accelerated bacterial activity.

Graphene has numerous advantages as a dental implant, and the limitations of graphene such as its minimal antibacterial effects have been vastly improved through incorporation with chitosan. Therefore, we demonstrate that graphene has good potential as a promising alternative to traditional surface treatments, and a graphene-incorporated implant might be used for fabrication of a dental implant with high osseointegration ability.

\section{Conclusions}

In this study, we propose a GC hybrid dental implant with enhanced antibacterial and cell proliferation properties. Using a spin-coating technique, GC nanocomposites with various 
concentrations were successfully coated onto the surfaces of a titanium implant, and the surface properties, including wettability and roughness, were changed. The GC hybrid implant suppressed bacterial activity and biofilm formation, and also enhanced the proliferation of osteoblasts. These findings provide a rational design for the development of a hybrid dental implant, which can also be extended to the development of other implants with changed surface properties. In particular, the proposed GC hybrid dental implant can be used as an effective implant scaffold for achieving enhanced osseointegration.

Supplementary Materials: The following are available online at http://www.mdpi.com/2076-3417/10/14/4888/s1: Figure S1: Effects of graphene-chitosan hybrid implants on bacterial activity. (a) Confocal microscopy images of $S$. aureus on pure glass and a $1 \%$ graphene-chitosan hybrid glass substrate. (b) Confocal microscopy images of S. mutans on pure titanium and a 1\% graphene-chitosan hybrid titanium substrate. Figure S2: Effects of graphene-chitosan hybrid implants on the attachment of mammalian cells. Table S1. Composition of artificial saliva

Author Contributions: Conceptualization, H.-P.L. and J.K.; methodology, H.-P.L. and J.K.; software, H.K. and S.P.; validation, H.K., S.P., M.-K.J., H.-P.L., and J.K.; formal analysis, S.P., H.K., K.S.C., S.K., and Y.G.; investigation, H.K. and S.P.; resources, S.P., H.K., K.S.C., C.P., and S.K.; data curation, H.K. and S.P.; writing-original draft preparation, H.K. and S.P.; writing-review and editing, H.K. and S.P.; visualization, H.K. and S.P.; supervision, J.K.; project administration, H.-P.L. and J.K.; funding acquisition, H.-P.L. and J.K.; All authors have read and agreed to the published version of the manuscript.

Funding: This work was supported by National Research Foundation of Korea (NRF) grants funded by the Korea government (2019R1I1A3A0106345 and NRF-2019M3A9H1103737). This work was also supported by the Korea Institute of Planning and Evaluation for Technology in Food, Agriculture and Forestry (IPET) through the Agriculture, Food and Rural Affairs Research Center Support Program, funded by the ministry of Agriculture, Food and Rural Affairs (MAFRA) (Project No. 714002). This work was supported by the National Research Foundation of Korea (NRF) grant funded by the Korean government (MSIP) (No. 2020R1F1A1076982). This study was supported by a grant (BCRI19043) of Chonnam National University Hospital Biomedical Research Institute.

Conflicts of Interest: The authors declare no conflict of interest. The funders had no role in the design of the study; in the collection, analyses, or interpretation of data; in the writing of the manuscript; or in the decision to publish the results.

\section{References}

1. Smeets, R.; Stadlinger, B.; Schwarz, F.; Beck-Broichsitter, B.; Jung, O.; Precht, C.; Kloss, F.; Gröbe, A.; Heiland, M.; Ebker, T. Impact of dental implant surface modifications on osseointegration. BioMed Res. Int. 2016, 2016. [CrossRef] [PubMed]

2. Park, C.; Park, S.; Lee, D.; Choi, K.S.; Lim, H.-P.; Kim, J. Graphene as an enabling strategy for dental implant and tissue regeneration. Tissue Eng. Regen. Med. 2017, 14, 481-493. [CrossRef]

3. Branemark, P.-I. Osseointegrated implants in the treatment of the edentulous jaw. Experience from a 10-year period. Scand. J. Plast. Reconstr. Surg. Suppl. 1977, 16, 1-132. [PubMed]

4. Liu, X.; Chen, S.; Tsoi, J.K.; Matinlinna, J.P. Binary titanium alloys as dental implant materials-A review. Regen. Biomater. 2017, 4, 315-323. [CrossRef] [PubMed]

5. Heo, D.N.; Ko, W.-K.; Lee, H.R.; Lee, S.J.; Lee, D.; Um, S.H.; Lee, J.H.; Woo, Y.-H.; Zhang, L.G.; Lee, D.-W.; et al. Titanium dental implants surface-immobilized with gold nanoparticles as osteoinductive agents for rapid osseointegration. J. Colloid Interface Sci. 2016, 469, 129-137. [CrossRef]

6. Ad Hoc Committee for the Development of Dental Implant Guidelines. Guidelines for the provision of dental implants. Int. J. Oral Maxillofac. Implants 2008, 23, 471.

7. Davies, J. Mechanisms of endosseous integration. Int. J. Prosthodont. 1998, 11, 391-401.

8. Persson, L.G.; Berglundh, T.; Lindhe, J.; Sennerby, L. Re-osseointegration after treatment of peri-implantitis at different implant surfaces: An experimental study in the dog. Clin. Oral Implants Res. 2001, 12, $595-603$. [CrossRef]

9. Lindhe, J.; Meyle, J. Peri-implant diseases: Consensus report of the sixth European workshop on periodontology. J. Clin. Periodontol. 2008, 35, 282-285. [CrossRef]

10. Mendonça, G.; Mendonça, D.B.; Aragao, F.J.; Cooper, L.F. Advancing dental implant surface technology-from micron-to nanotopography. Biomaterials 2008, 29, 3822-3835. [CrossRef] 
11. Souza, J.C.; Sordi, M.B.; Kanazawa, M.; Ravindran, S.; Henriques, B.; Silva, F.S.; Aparicio, C.; Cooper, L.F. Nano-scale modification of titanium implant surfaces to enhance osseointegration. Acta Biomater. 2019, 94, 112-131. [CrossRef] [PubMed]

12. Pilliar, R.M. Overview of surface variability of metallic endosseous dental implants: Textured and porous surface-structured designs. Implant Dent. 1998, 7, 305-314. [CrossRef]

13. Tinsley, D.; Watson, C.J.; Russell, J.L. A comparison of hydroxylapatite coated implant retained fixed and removable mandibular prostheses over 4 to 6 years. Clin. Oral Implants Res. 2001, 12, 159-166. [CrossRef] [PubMed]

14. Asensio, G.; Vázquez-Lasa, B.; Rojo, L. Achievements in the topographic design of commercial titanium dental implants: Towards anti-peri-implantitis surfaces. J. Clin. Med. 2019, 8, 1982. [CrossRef] [PubMed]

15. Povimonsky, A.G.; Rapaport, H. Peptide coating applied on the spot improves osseointegration of titanium implants. J. Mater. Chem. B 2017, 5, 2096-2105. [CrossRef] [PubMed]

16. Sun, S.; Zhang, Y.; Zeng, D.; Zhang, S.; Zhang, F.; Yu, W. PLGA film/Titanium nanotubues as a sustained growth factor releasing system for dental implants. J. Mater. Sci. Mater. Med. 2018, 29, 141. [CrossRef] [PubMed]

17. He, S.; Zhou, P.; Wang, L.; Xiong, X.; Zhang, Y.; Deng, Y.; Wei, S. Antibiotic-decorated titanium with enhanced antibacterial activity through adhesive polydopamine for dental/bone implant. J. Royal Soc. Interface 2014, 11, 20140169. [CrossRef]

18. Kim, N.-H.; Lee, S.-H.; Ryu, J.-J.; Choi, K.-H.; Huh, J.-B. Effects of rhBMP-2 on sandblasted and acid etched titanium implant surfaces on bone regeneration and osseointegration: Spilt-mouth designed pilot study. BioMed Res. Int. 2015, 2015. [CrossRef]

19. Brody, H. Graphene. Nature 2012, 483, S29. [CrossRef]

20. Novoselov, K.S.; Fal'ko, V.I.; Colombo, L.; Gellert, P.R.; Schwab, M.G.; Kim, K. A roadmap for graphene. Nature 2012, 490, 192-200. [CrossRef]

21. Kim, J.; Choi, K.S.; Kim, Y.; Lim, K.-T.; Seonwoo, H.; Park, Y.; Kim, D.-H.; Choung, P.-H.; Cho, C.-S.; Kim, S.Y.; et al. Bioactive effects of graphene oxide cell culture substratum on structure and function of human adipose-derived stem cells. J. Biomed. Mater. Res. Part A 2013, 101, 3520-3530. [CrossRef] [PubMed]

22. Kim, J.; Kim, Y.-R.; Kim, Y.; Lim, K.T.; Seonwoo, H.; Park, S.; Cho, S.-P.; Hong, B.H.; Choung, P.-H.; Chung, T.D. Graphene-Incorporated chitosan substrata for adhesion and differentiation of human mesenchymal stem cells. J. Mater. Chem. B 2013, 1, 933-938. [CrossRef] [PubMed]

23. Li, K.; Wang, C.; Yan, J.; Zhang, Q.; Dang, B.; Wang, Z.; Yao, Y.; Lin, K.; Guo, Z.; Bi, L.; et al. Evaluation of the osteogenesis and osseointegration of titanium alloys coated with graphene: An in vivo study. Sci. Rep. 2018, 8, 1843. [CrossRef]

24. Qiu, J.; Liu, L.; Zhu, H.; Liu, X. Combination types between graphene oxide and substrate affect the antibacterial activity. Bioact. Mater. 2018, 3, 341-346. [CrossRef] [PubMed]

25. Park, S.; Choi, K.S.; Kim, S.; Gwon, Y.; Kim, J. Graphene oxide-assisted promotion of plant growth and stability. Nanomaterials 2020, 10, 758. [CrossRef] [PubMed]

26. Lehner, B.A.E.; Janssen, V.A.E.C.; Spiesz, E.M.; Benz, D.; Brouns, S.J.J.; Meyer, A.S.; van der Zant, H.S.J. Creation of conductive graphene materials by bacterial reduction using shewanella oneidensis. ChemistryOpen 2019, 8, 888-895. [CrossRef]

27. Ranella, A.; Barberoglou, M.; Bakogianni, S.; Fotakis, C.; Stratakis, E. Tuning cell adhesion by controlling the roughness and wettability of 3D micro/nano silicon structures. Acta Biomater. 2010, 6, 2711-2720. [CrossRef]

28. Kocijan, A.; Conradi, M.; Hočevar, M. The influence of surface wettability and topography on the bioactivity of $\mathrm{TiO}(2) /$ Epoxy coatings on AISI 316L stainless steel. Materials 2019, 12, 1877. [CrossRef]

29. Park, S.; Park, H.-H.; Sun, K.; Gwon, Y.; Seong, M.; Kim, S.; Park, T.-E.; Hyun, H.; Choung, Y.-H.; Kim, J.; et al. Hydrogel nanospike patch as a flexible anti-pathogenic scaffold for regulating stem cell behavior. ACS Nano 2019, 13, 11181-11193. [CrossRef]

30. Singh, G. Surface treatment of dental implants: A review. J. Dent. Med. Sci. 2018, 17, 49-53. [CrossRef]

31. Meng, H.-W.; Chien, E.Y.; Chien, H.-H. Dental implant bioactive surface modifications and their effects on osseointegration: A review. Biomark. Res. 2016, 4, 24. [CrossRef] [PubMed]

32. Al Mugeiren, O.M.; Baseer, M.A. Dental implant bioactive surface modifiers: An update. J. Int. Soc. Prev. Community Dent. 2019, 9, 1-4. [CrossRef] [PubMed] 
33. Thompson, B.C.; Murray, E.; Wallace, G.G. Graphite oxide to graphene. Biomaterials to bionics. Adv. Mater. 2015, 27, 7563-7582. [PubMed]

34. Zhang, X.; Song, G.; Qiao, H.; Lan, J.; Wang, B.; Yang, H.; Ma, L.; Wang, S.; Wang, Z.; Lin, H.; et al. Novel ternary vancomycin/strontium doped hydroxyapatite/graphene oxide bioactive composite coatings electrodeposited on titanium substrate for orthopedic applications. Colloids Surf. A Physicochem. Eng. Asp. 2020, 603, 125223. [CrossRef]

35. Park, S.; Kim, T.; Gwon, Y.; Kim, S.; Kim, D.; Park, H.-H.; Lim, K.-T.; Jeong, H.E.; Kim, K.; Kim, J. Graphene-Layered eggshell membrane as a flexible and functional scaffold for enhanced proliferation and differentiation of stem cells. ACS Appl. Bio Mater. 2019, 2, 4242-4248. [CrossRef]

36. Park, S.; Choi, K.S.; Kim, W.; Lee, D.; Kim, D.; Kim, M.-S.; Kim, K.; Kim, J. Engineering nanowrinkled microfibers composed of eggshell membrane and graphene. Mater. Lett. 2018, 229, 78-81. [CrossRef]

37. Truong, V.; Webb, H.; Fadeeva, E.; Chichkov, B.; Wu, A.; Lamb, R.; Wang, J.; Crawford, R.; Ivanova, E. Air-Directed attachment of coccoid bacteria to the surface of superhydrophobic lotus-like titanium. Biofouling 2012, 28, 539-550. [CrossRef]

38. Kim, W.; Kim, D.; Park, S.; Lee, D.; Hyun, H.; Kim, J. Engineering lotus leaf-inspired micro- and nanostructures for the manipulation of functional engineering platforms. J. Ind. Eng. Chem. 2018, 61, 39-52. [CrossRef]

39. Li, Q.; Yong, C.; Cao, W.; Wang, X.; Wang, L.; Zhou, J.; Xing, X. Fabrication of charge reversible graphene oxide-based nanocomposite with multiple antibacterial modes and magnetic recyclability. J. Colloid Interface Sci. 2018, 511, 285-295. [CrossRef]

40. Kravanja, G.; Primožič, M.; Knez, Ž.; Leitgeb, M. Chitosan-based (Nano) materials for novel biomedical applications. Molecules 2019, 24, 1960. [CrossRef]

41. Liu, X.F.; Guan, Y.L.; Yang, D.Z.; Li, Z.; Yao, K.D. Antibacterial action of chitosan and carboxymethylated chitosan. J. Appl. Polym. Sci. 2001, 79, 1324-1335.

42. Varma, A.; Deshpande, S.; Kennedy, J. Metal complexation by chitosan and its derivatives: A review. Carbohydr. Polym. 2004, 55, 77-93. [CrossRef]

43. Sudarshan, N.; Hoover, D.; Knorr, D. Antibacterial action of chitosan. Food Biotechnol. 1992, 6, $257-272$. [CrossRef]

44. Li, S.; Cui, S.; Yin, D.; Zhu, Q.; Ma, Y.; Qian, Z.; Gu, Y. Dual antibacterial activities of a chitosan-modified upconversion photodynamic therapy system against drug-resistant bacteria in deep tissue. Nanoscale 2017, 9 , 3912-3924. [CrossRef] [PubMed]

45. Liu, S.; Hu, M.; Zeng, T.; Wu, R.; Jiang, R.; Wei, J.; Wang, L.; Kong, J.; Chen, Y. Lateral dimension-dependent antibacterial activity of graphene oxide sheets. Langmuir 2012, 28, 12364-12372. [CrossRef] [PubMed]

46. Alayande, A.; Chae, S.; Kim, S. Surface morphology-dependent spontaneous bacterial behaviors on graphene oxide membranes. Sep. Purif. Technol. 2019, 226, 68-74. [CrossRef] 